\title{
Readequação de territórios da política de assistência social na cidade de Montes Claros-MG
}

\author{
Readjustment territories of social assistance policy in the city of light-MG hills
}

\section{Resumo:}

A pesquisa que originou este artigo teve como objetivo analisar a eficácia da divisão territorial da malha urbana de Montes Claros/MG, no atendimento ao público demandante considerando as aproximações e distanciamentos dos CRAS em relação a seu público alvo. A metodologia utilizada foi a pesquisa quanti-qualitativa, em que a representação da malha urbana de Montes Claros teve como base o uso de técnicas de geoprocessamento, em que o banco de dados do censo do IBGE do ano de 2010, integrado à base cartográfica da área urbana no software ArcGis 10.1, possibilitou a representação de dados socioeconômicos através de mapas temáticos. A análise de discurso, a partir de entrevistas semiestruturadas, junto às assistentes sociais, possibilitou as conclusões necessárias à investigação a que se propunha. Constatou-se, segundo afirmação das/dos assistentes sociais e análises destas afirmações, que o melhor atendimento aos segmentos demandantes dar-se-á através da reconfiguração territorial de Polos extensos que excedem o número limite de famílias de baixa renda, determinado pela Política de Assistência Social para o porte do município, fragmentando-os e implantando-se uma nova unidade de CRAS em cada novo fragmento. Aos Polos contendo população dispersa propôsse a adoção de equipes volantes de atendimento socioassistencial em atendimento às demandas.
\end{abstract}

Angélica de Santana Rocha * Marcos Esdras Leite ${ }^{* *}$

Palavras-chave: Geotecnologias. Território. CRAS. Avaliação. reconfiguração.

\begin{abstract}
:
This study aimed to analyze the effectiveness of the territorial division of the urban area of Montes Claros / MG to meeting the demands that it presents, considering the similarities and differences of CRAS in relation to your target group. The methodology used was quantitative and qualitative research, in which the representation of the urban area of Montes Claros were based on the use of GIS techniques, in the database year 2010 IBGE census, integrated into the base map of the urban area in ArcGIS 10.1 software, enabled the representation of socio-economic data through thematic maps. The discourse analysis, from semi-structured interviews with the welfare worker, enabled this work the necessary conclusions to the investigation as proposed. It was found, according to assertion of welfare workers and analysis of these statements taken by this research that the best service to the segments will be given through the territorial reconfiguration extensive poles that exceed the limited number of lowincome families, as determined by the Social assistance Policy for the size of the city, fragmenting them and implanting a new CRAS unit in each new fragment.
\end{abstract}

\footnotetext{
* Mestre em Desenvolvimento Social pela Universidade Estadual de Montes Claros - UNIMONTES. E-mail: angelica.srocha@hotmail.com

** Professor do Departamento de Geociências da Universidade Estadual de Montes Claros - UNIMONTES Doutor em Geografia pela Universidade Federal de Uberlândia. E-mail: marcosesdrasleite@gmail.com
} 
The Poles containing dispersed population proposed the adoption of mobile teams of social assistance service in meeting the demands.

Keywords: Geo. Urban territory. CRAS. Evaluation. Reconfiguration.

\section{Introdução}

Este artigo apresenta o resultado da pesquisa desenvolvida no contexto do curso de Mestrado em Desenvolvimento Social, na cidade de Montes Claros - MG. A qual questionou-se a eficácia da divisão territorial da malha urbana para implante das unidades de Centro de Referência de Assistência Social-CRAS no atendimento às demandas que esta apresenta, considerando as aproximações e distanciamentos dos CRAS em relação a seu público alvo.

Os territórios para abrangência de cada unidade de CRAS no município foram definidos no ano de 2006. Esta divisão territorial permanece em vigor até o presente momento. O problema de pesquisa questionou se esta configuração territorial atende atualmente aos segmentos populacionais demandantes, que podem ter sofrido reconfigurações ao longo do período que compreende a delimitação dos territórios e o momento presente.

Foram analisados a extensão dos polos regionais, o número de setores censitários ou loteamentos que compõem cada território e a locação dos CRAS em relação aos segmentos, facilitando ou não o acesso a atividades que venham a ser desenvolvidas no espaço físico da unidade, como serviços de convivência, reuniões e deslocamento semanal em função do Programa de Aquisição de Alimentos - PAA.

Averiguar os pontos propostos acima se justifica pelo fato de que a Política Nacional de Assistência Social - PNAS - afirma que as unidades de CRAS devem se alocar em áreas de baixa renda e estar acessíveis ao público alvo, administrando Programas, Projetos e Serviços de atendimento social. Prevê a busca ativa no interior desses territórios, em que a equipe de referência não apenas aguarda que a demanda chegue à unidade, mas se locomove pelo território, levando informações e buscando cadastrar novas famílias que se caracterizem como demanda.

O CRAS é, assim, a unidade representativa do Estado que se aproxima do cidadão com a finalidade de garantir a este acesso aos benefícios oriundos da assistência social. Assistência esta que legalmente supera o viés de caridade, filantropia, benesse, favor e alcança o patamar de política pública, ligada ao sistema de seguridade social, 
normatizada enquanto sistema único e financiada pela União, Estados, Municípios e Distrito Federal, de modo que a prestação de serviços se dê em caráter continuado. Neste contexto se insere o Serviço Social, que adota a correlação de forças entre atores sociais com o seu objeto de intervenção e a/o assistente social figura neste espaço como agente intermediária/o entre as ações da política pública de Assistência e o cidadão que a esta recorre.

Neste sentido, sabendo que a assistência figura como direito de cidadania e deve estar próxima de seu público alvo, facilitando acesso e adesão a seus benefícios; sabendo que avaliações constantes das ações de assistência devem ser empreendidas em prol de se verificar as alterações no cenário que comporta os sujeitos demandantes, construiu-se o problema de pesquisa para este trabalho. Cujo objetivo geral foi questionar a eficácia da divisão territorial da malha urbana de Montes Claros para locação de unidades de CRAS no atendimento aos segmentos populacionais demandantes. Os objetivos específicos foram verificar particularidades dos territórios que dificultam o acesso do público alvo à unidade de CRAS e observar junto aos assistentes sociais a necessidade de reconfiguração territorial.

Quanto à metodologia para construção do trabalho, utilizou-se inicialmente técnicas de geoprocessamento para construção do mapa dos territórios dos CRAS definidos no ano de 2006, bem como para construir a simulação da nova proposta de território a partir da visão das assistentes sociais. Os dados disponíveis no Censo do IBGE, do ano de 2010, foram espacializados através do Sistema de Informação Geográfica - SIG - "que trabalha com banco de dados alfanuméricos ligado a uma base cartográfica, para consequente espacialização desses dados [...], resultando assim em mapas temáticos ou gráficos para análise de um determinado fenômeno" (LEITE, 2006, p.47). Foram usados os microdados do IBGE, apresentados por setores censitários, juntamente com a base cartográfica digital, também disponibilizada pelo IBGE.

O segundo aspecto metodológico diz respeito ao trabalho de campo, em que assistentes sociais foram questionadas/os quanto ao atendimento às demandas apresentadas por seus territórios de atuação, tendo em vista a dimensão territorial e as particularidades destes, tais como presença ou não de favelas, vazios urbanos ou outros fatores que dificultem o acesso do público alvo à unidade ou o trabalho de busca ativa a se realizar pela equipe técnica dos CRAS. As entrevistas foram agendadas através da 
coordenação de cada unidade de CRAS, segundo à disponibilidade das/dos profissionais em atender a esta. Concluiu-se que há necessidade de reconfiguração dos territórios extensos e construiu-se ao final da pesquisa a simulação do novo território urbano da Política de Assistência Social.

\section{A formação de territórios de atuação de políticas públicas}

Tanto a Política de saúde como a Política de assistência social têm na territorialização uma etapa basilar de implemento de suas ações. Territorialização que se dá a partir do levantamento de dados quanto a características epidemiológicas - caso da saúde - sociais e econômicas - caso da assistência social - comuns a determinadas áreas, a partir de suas ocupações, transformando-as em territórios de sua ação (FARIA; BORTOLOZZI, 2009). No caso específico da Política de Assistência Social, áreas marcadas pela presença de famílias de baixa renda, propensas ao risco e vulnerabilidades sociais, segundo a mesma Política.

A Política Nacional de Assistência Social tem na formação de territórios para atuação das unidades de CRAS uma das bases que configuram a presença interventora do Estado junto aos segmentos em risco e vulnerabilidade social. Justificada pelo Ministério do Desenvolvimento Social e Combate à Fome a partir do argumento de que, os benefícios provenientes desta ação interventora devem estar alocados o mais próximo possível do local de vivências do público alvo, considerando que a sua inserção e mobilidade neste território se dá de maneiras diferenciada. O que exige adoção de estratégias que se adequem à realidade de cada território.

A delimitação dos territórios para atuação da Política de Assistência se dá a partir de diagnóstico social em que são observados fatores e indicadores tais como: "a questão fundiária, as formas de ocupação territorial e segregação/exclusão espacial, o mercado imobiliário" (BRASIL, 2008, p. 49); aspectos populacionais como a população total nas zonas urbana e rural; densidade demográfica; taxas de natalidade e mortalidade; mortalidade infantil; longevidade; média de filhos por família; distribuição da população por sexo e faixa etária (BRASIL, 2008).

Observa-se indicadores de educação: "escolaridade da população jovem e adulta, dos chefes de família, índices de analfabetismo, crianças fora da escola ou com distorção de idade-série, índices de evasão e reprovação, dente outros (BRASIL, 2008, p. 50). Há 
casos, porém, em que diagnosticar a realidade a partir da análise dos indicadores listados se torna tarefa muito complexa. Diante disto a Política determina o implante de unidades de CRAS em áreas de concentração de baixa renda, famílias cuja renda per capita mensal seja de até $1 / 2$ salário mínimo. Consideram-se dentre as famílias de baixa renda as que se encontram em situações de risco e vulnerabilidade social.

A delimitação de territórios e a previsão das ações de assistência devem constar no Plano Municipal de Assistência Social, em que se toma como base para formatação de programas, projetos e serviços as diretrizes previstas pelo Sistema Único de Assistência Social - SUAS. As ações de assistência no território são previstas de maneira a funcionar em rede com outras instituições públicas tais como de saúde, educação, profissionalização; ou privados, como ONG, associações e grupos civis, de maneira a atender à diversidade das demandas que o território apresentar.

\section{Avaliação dos territórios da política de assistência social em Montes Claros - MG}

Rodrigues et al. (2012) apresenta que para locação das unidades de CRAS nas áreas mais vulneráveis, a cidade foi dividida, no ano de 2006 em 12 polos urbanos e um rural, em que cada grande região receberia uma unidade de CRAS. O SUAS se materializa assim em Montes Claros através de 11 unidades de CRAS distribuídas pelos polos Maracanã, Delfino Magalhães, Major Prates, Santos Reis, JK/Village, Vila Oliveira, Independência, São Judas Tadeu, Renascença, Polo Central e Polo Rural. Observa-se na figura 01 os 12 polos em que se dividiu a malha urbana para criação das políticas de Saúde e Assistência Social. 
Figura 01 - Mapa dos loteamentos que compõem os polos urbanos de Montes Claros - MG.

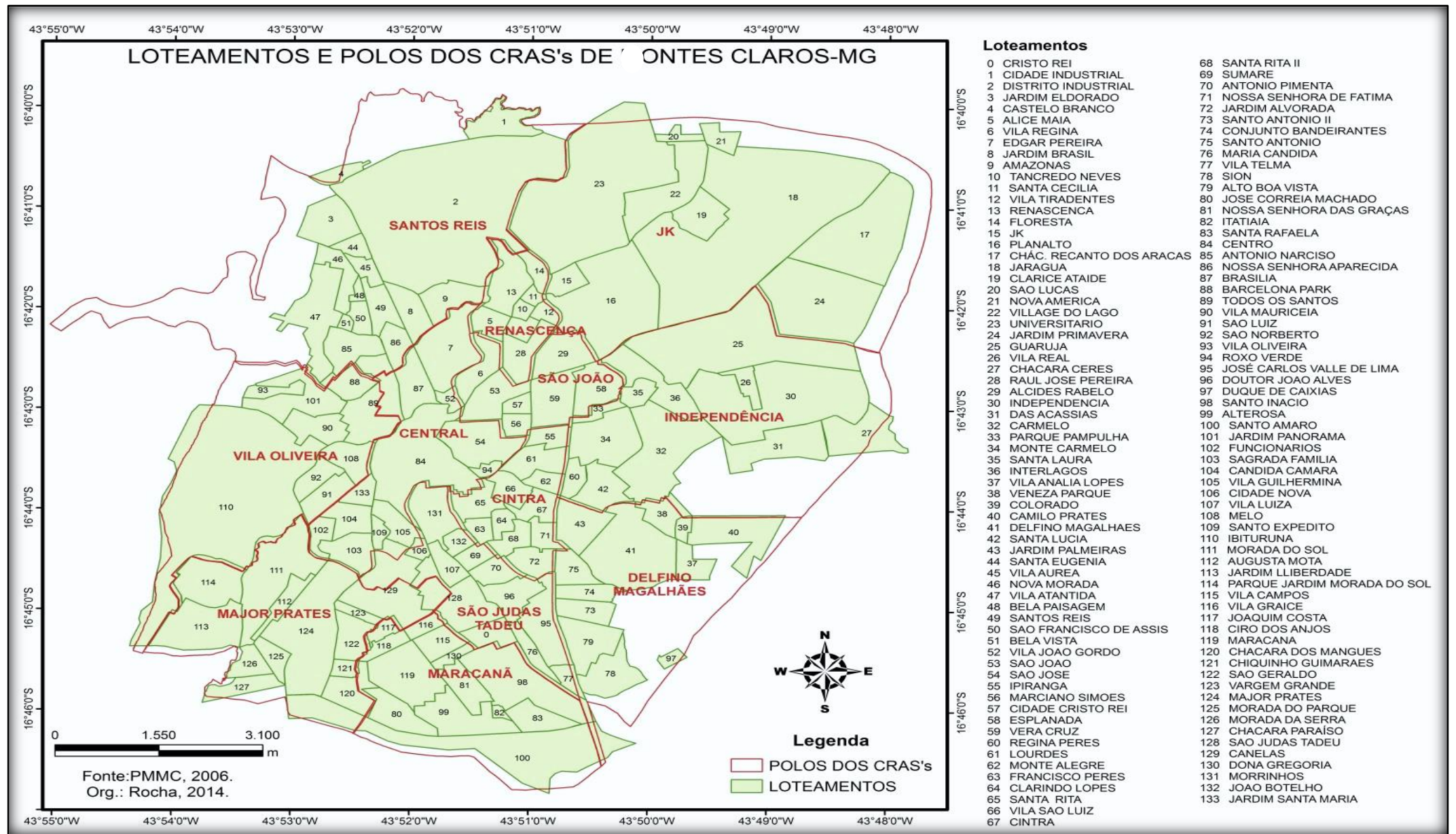

Fonte: Rocha, 2015

O primeiro item avaliado foi a extensão dos territórios, bem como o número de setores censitários que os compõem. Observa-se inicialmente disparidades de extensão entre os polos, em que o maior deles, polo Jk, possui extensão de 20,86 km², ao passo que o menor polo, Renascença, possui extensão de $1.98 \mathrm{~km}^{2}$, conforme demonstram a figura 02 e a tabela 01 . 


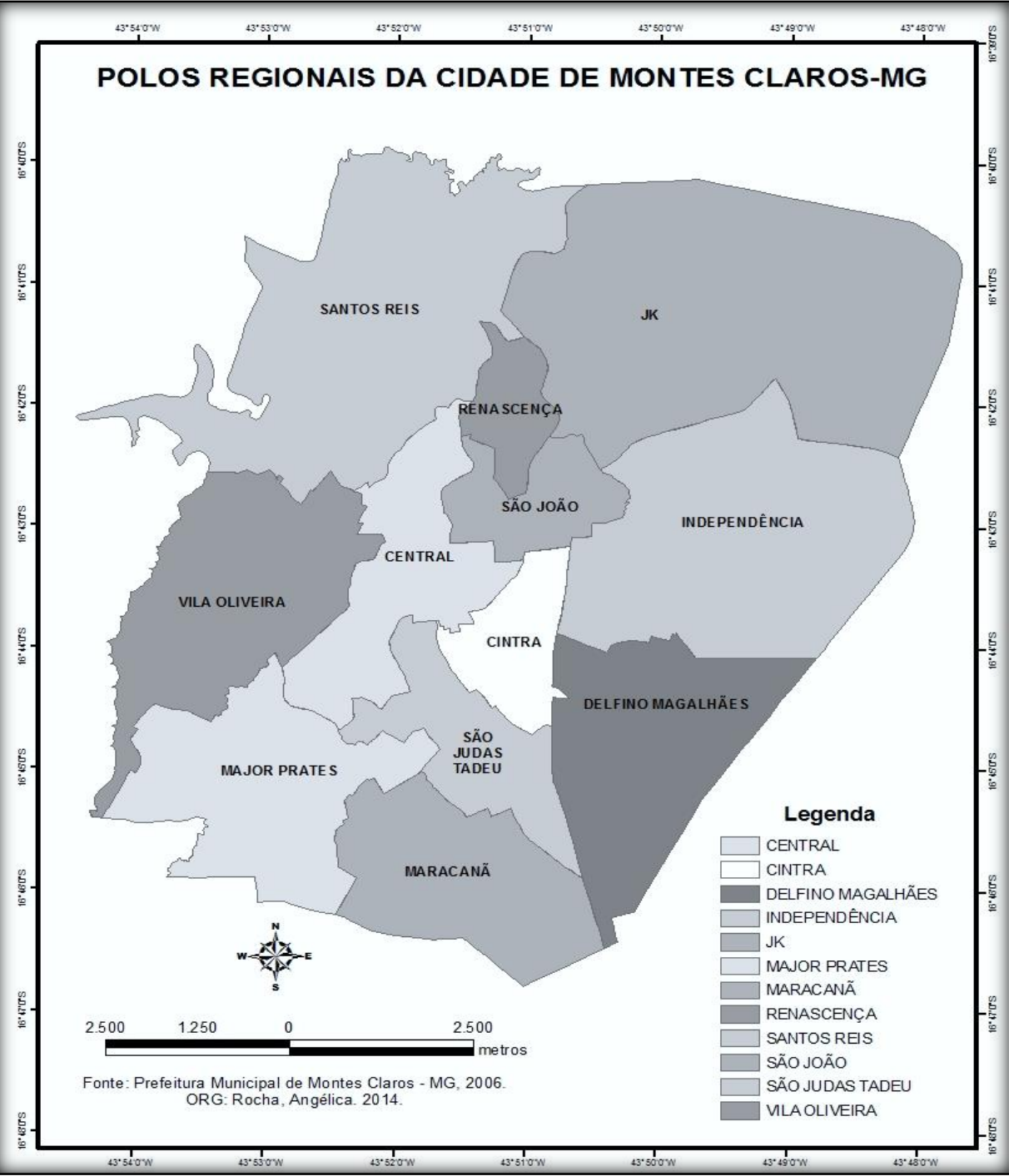

\begin{tabular}{l|c} 
Polo Regional & $\begin{array}{c}\text { Extensão Total } \\
\text { do Polo } \mathrm{Km}^{2}\end{array}$ \\
$\mathrm{Jk}$ & 20,86 \\
Santos Reis & 17.57 \\
Independência & 14.01 \\
\hline Delfino & $8.8 \mathrm{~B}$ \\
Magalhães & \\
\hline Vila Oliveira & 8,81 \\
\hline Major Prates & 8,43 \\
Maracanã & 7.49 \\
Central & 6.13 \\
são Judas & 4.42 \\
Tadeu & \\
são João & 2.98 \\
Cintra & 2.89 \\
Renascença & 1.98
\end{tabular}

Fonte: Rocha; Leite, 2014 
Os polos Independência, Jk e Santos Reis se destacam, conforme o mapa, pela grande extensão; os polos São João, Renascença e Cintra se destacam pela pequena extensão. Quanto ao número de setores censitários que compõem cada polo se faz necessária a notificação de que o município adota uma divisão de seu território citadino em loteamentos para fins de gestão local, porém esta configuração é conhecida apenas pelos técnicos que atuam no âmbito da gestão municipal. A população desconhece tal divisão (LEITE; BRITO,2012) e usa em seu dia a dia o termo "bairro", que não condiz com a realidade adotada pelo município. O termo "bairro" é adotado também pelos diversos profissionais que compõem o corpo de servidores do município. O modelo de divisão municipal em loteamentos difere também do que adota o IBGE para fins de coleta de dados, ou seja, divisão em setores censitários (LEITE; BRITO, 2012).

Observando-se o número de loteamentos que compõem cada território de CRAS tem-se uma distribuição de maneira que os polos Santos Reis, Major Prates e Independência englobam as maiores quantidades dentre os polos regionais, sendo estas 22, 19 e 18 loteamentos, respectivamente; enquanto os polos Cintra e São João são compostos pelas menores quantidades dentre os polos, sendo estas 11 e 7 loteamentos, respectivamente.

Entrevistado um gestor municipal do período 2005 a 2008, este afirmou que na realidade não houve estudos geográficos ou socioeconômicos profundos para direcionar a divisão territorial da malha urbana para implante das políticas públicas. Dada a urgência em garantir que o município recebesse os recursos para tais políticas, a divisão territorial ocorreu de maneira aleatória, sem critérios específicos condutores, o que explica as disparidades observadas. Pereira et al. (2010) em seus estudos sobre a cidade afirmam que as leis e planos municipais de Montes Claros refletem uma cultura de planejamentos que não levam em consideração a participação popular ou mesmo os aspectos específicos do município, em uma visão holística do mesmo.

A tabela 02 demonstra a disparidade numérica na distribuição dos setores censitários e loteamentos para composição dos polos regionais, ratificando a afirmação acima. Observa-se nesta tabela situações como o polo Santos Reis composto por 47 unidades censitárias segundo o IBGE, ou 22 loteamentos segundo critério utilizado pelo município, enquanto o polo São João se compõe por 24 unidades censitárias ou 7 loteamentos. 
Tabela 02: Número de setores censitários e loteamentos que compõem os territórios dos CRAS

\begin{tabular}{l|c|c}
\hline \multicolumn{1}{c|}{ Polo Regional } & $\begin{array}{c}\text { № de Setores } \\
\text { Censitários } \\
\text { IBGE }\end{array}$ & $\begin{array}{c}\text { № de Loteamentos } \\
\text { Municipais }\end{array}$ \\
\hline Santos Reis & 47 & 22 \\
\hline Major Prates & 40 & 19 \\
\hline Independência & 31 & 18 \\
\hline Central & 51 & 17 \\
\hline Jk & 27 & 17 \\
\hline Delfino Magalhães & 35 & 17 \\
\hline São Judas & & 11 \\
\hline Tadeu & 38 & 07 \\
\hline Maracanã & 39 & 15 \\
\hline Vila Oliveira & 13 & 14 \\
\hline Renascença & & \\
\hline Cintra & 33 & 17 \\
\hline São João & & \\
\hline
\end{tabular}

Fontes: IBGE-Censo Demográfico de 2010; Secretaria de Desenvolvimento Social, Montes Claros

Quanto a locação dos CRAS em relação aos segmentos demandantes, segundo item avaliado neste trabalho, se observa nas figuras 03, 04 e 05 aproximações e distanciamentos destes em relação à unidade. A figura 03 permite a visualização de que as unidades de CRAS se encontram alocadas em áreas de maior vulnerabilidade social, em que o número de domicílios de baixa renda são de 74 a 111 e de 112 a 183, cumprindo assim o que determina a Política de Assistência Social, excetuando-se apenas os polos Cintra e São João, que não possuem em seu território unidade de CRAS que atenda a estes de maneira individualizada. O Polo Cintra é atendido pelo CRAS Central e o Polo São João é atendido pelo CRAS Renascença. Embora para a prestação de serviços de assistência social os polos Cintra e São João se unam aos polos Central e Renascença, para atendimento dos serviços de saúde estes figuram como polos individualizados 
Figura 03 - Mapa de locação das unidades de CRAS em relação aos domicílios de baixa renda da cidade de Montes Claros -MG

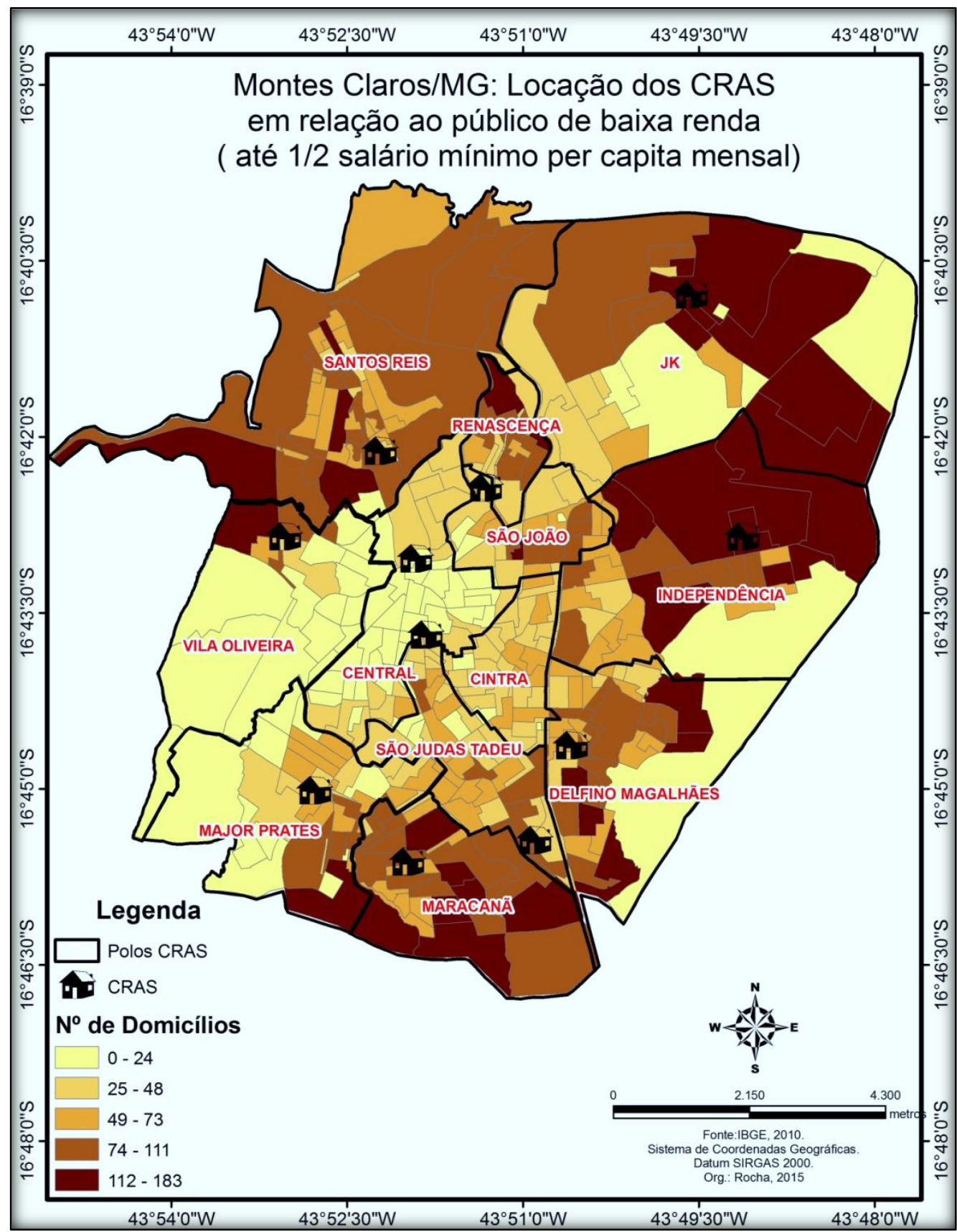

Fonte: Rocha, 2016

A figura 04 demonstra a locação das unidades de CRAS em relação ao segmento idoso acima de 65 anos. Faz-se pertinente pontuar que o critério utilizado pela Política Nacional de Assistência Social para locação das unidades de CRAS é a renda. As unidades se fixam em áreas de maior vulnerabilidade. Este trabalho se volta a verificar as aproximações e os distanciamentos em relação a segmentos específicos na variável baixa renda - idosos a partir de 65 anos, pessoas com deficiências, jovens entre 15 a 29 
anos - com intuito de verificar se a configuração territorial para locação das unidades de CRAS adotada pelo município facilita ou dificulta o acesso destes segmentos populacionais de baixa renda aos serviços prestados na unidade.

A figura 04 demonstra que as unidades de CRAS presentes nos polos Maracanã, Delfino Magalhães, Independência, Jk e Santos Reis, devido à extensão que possuem, ora apresentam aproximações e ora apresentam distanciamentos em relação ao público idoso a partir de 65 anos, dependendo da localidade onde residam. Idosos residentes em setores que se localizam em pontos extremos destes territórios encontram dificuldades em participar de atividades que venham a ser desenvolvidas na unidade de CRAS.

Como se pode observar na figura 04, os polos Delfino Magalhães, Independência e Jk possuem em seus extremos setores contendo número de 71 a 99 pessoas idosas acima de 65 anos, residentes em áreas de baixa renda, distanciados da unidade de CRAS. O polo São Judas tem a unidade de CRAS alocada a sul, e sua população idosa a partir de 65 anos se concentra no centro e a oeste no polo, configurando distanciamento da unidade em relação a estas concentrações.

O polo Cintra possui em seu centro setores com concentrações maiores do segmento, cujo número se encontra entre 71 e 99 pessoas e 100 a 157 pessoas, porém não possui neste território unidade de CRAS que a atenda, estando esta alocada na região central, que possui o maior número de idosos dentre os polos regionais, mas não se configura como área de baixa renda. O polo Renascença, devido a pequena extensão que possui, se aproxima dos setores com maior concentração deste segmento. Os polos Santos Reis, Vila Oliveira, Maracanã e Major Prates possuem unidades de CRAS próximas aos setores em que se concentram o maior número de idosos. 
Figura 04 - Mapa de locação das unidades de CRAS em relação aos idosos a partir de 65 anos da cidade de Montes Claros - MG.

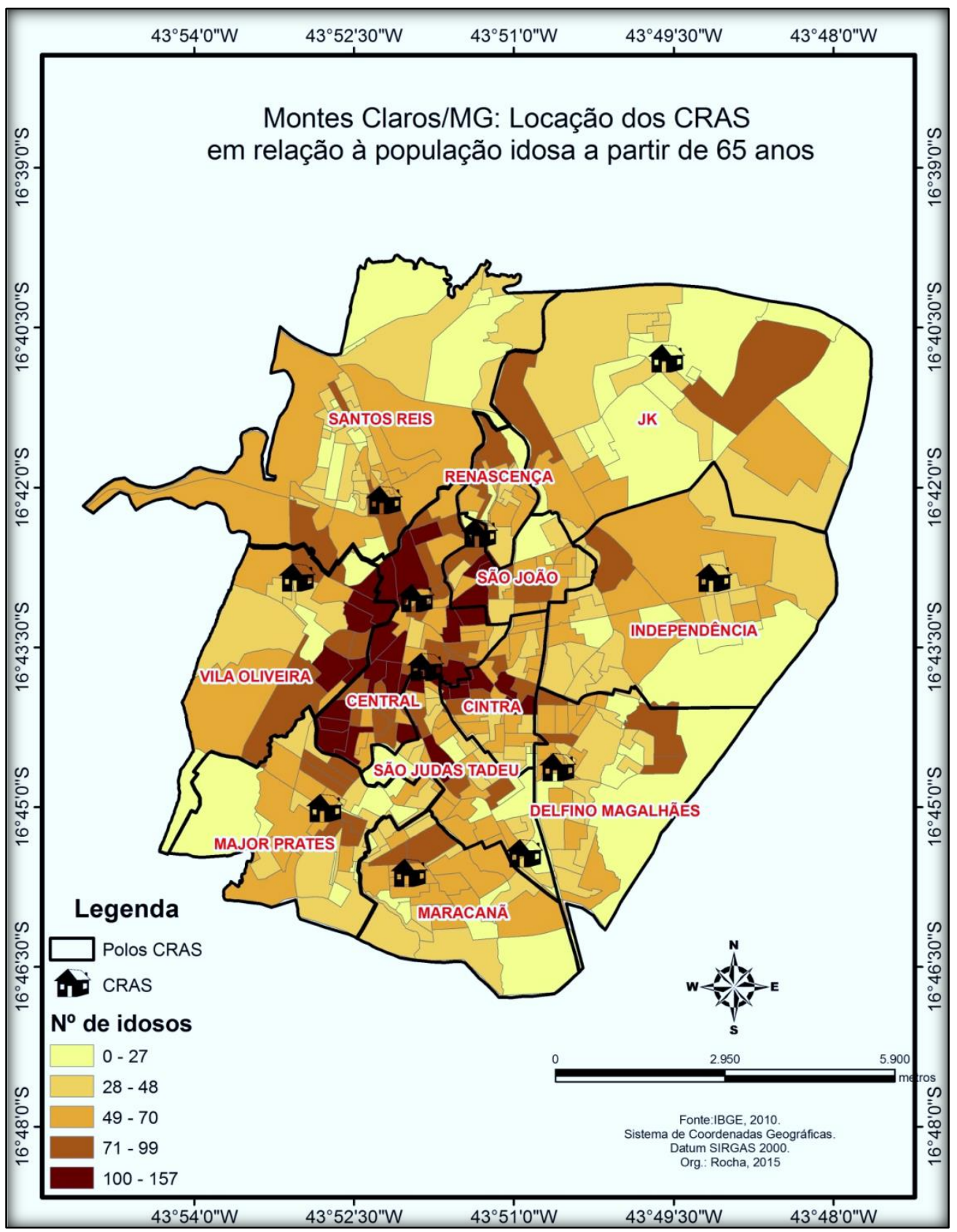

Fonte: Rocha, 2016

A figura 05 demonstra a locação das unidades de CRAS em relação ao público jovem com faixa etária de 15 a 29 anos. Assim como se observa na figura 04, a figura 05 demonstra aproximações e distanciamentos em relação ao público demandante. Jovens residentes em setores que se encontram em pontos extremos dos territórios extensos podem encontrar empecilhos no acesso às informações e aos serviços a eles destinados, que venham a ser desenvolvidos na unidade de CRAS. 
O polo cuja unidade está próxima aos setores que apresentam maiores concentrações de jovens de baixa renda é o polo Vila Oliveira, devido às especificidades do território e da quantidade de jovens que o polo apresenta. No polo Vila Oliveira a quantidade de jovens é alta, porém poucos se configuram como baixa renda, sendo residentes nos loteamentos Vila Oliveira, Vila Mauriceia, Panorama I e Panorama II, setores vulneráveis no polo, atendidos pela assistência Social. Os demais são caracterizados pela presença de famílias de alta renda.

Os polos Maracanã, Delfino Magalhães, Independência, Jk e Santos Reis, devido à extensão que apresentam, possuem setores em seus extremos cujo número de jovens é de 413 a 635 pessoas, que se encontram distanciados da unidade de CRAS. A distância em que se encontra a unidade de CRAS em relação aos segmentos demandantes pode representar problema de acesso uma vez que os segmentos vulnerabilizados não dispõem de meios próprios de transporte e o nível de vulnerabilidade pode ser tal que impeça acesso até mesmo ao transporte público. O trabalho de campo procurou verificar as ações que se desenvolvem nas unidades de CRAS em atendimento a estes segmentos, delimitados para este trabalho, questionando a configuração territorial de cada polo como problemática ou não ao desenvolvimento de tais ações. A próxima sessão a descreve os resultados obtidos. 
Figura 05 - Mapa de locação das unidades de CRAS em relação aos jovens com faixa etária de 15 a 29 anos da cidade de Montes Claros - MG

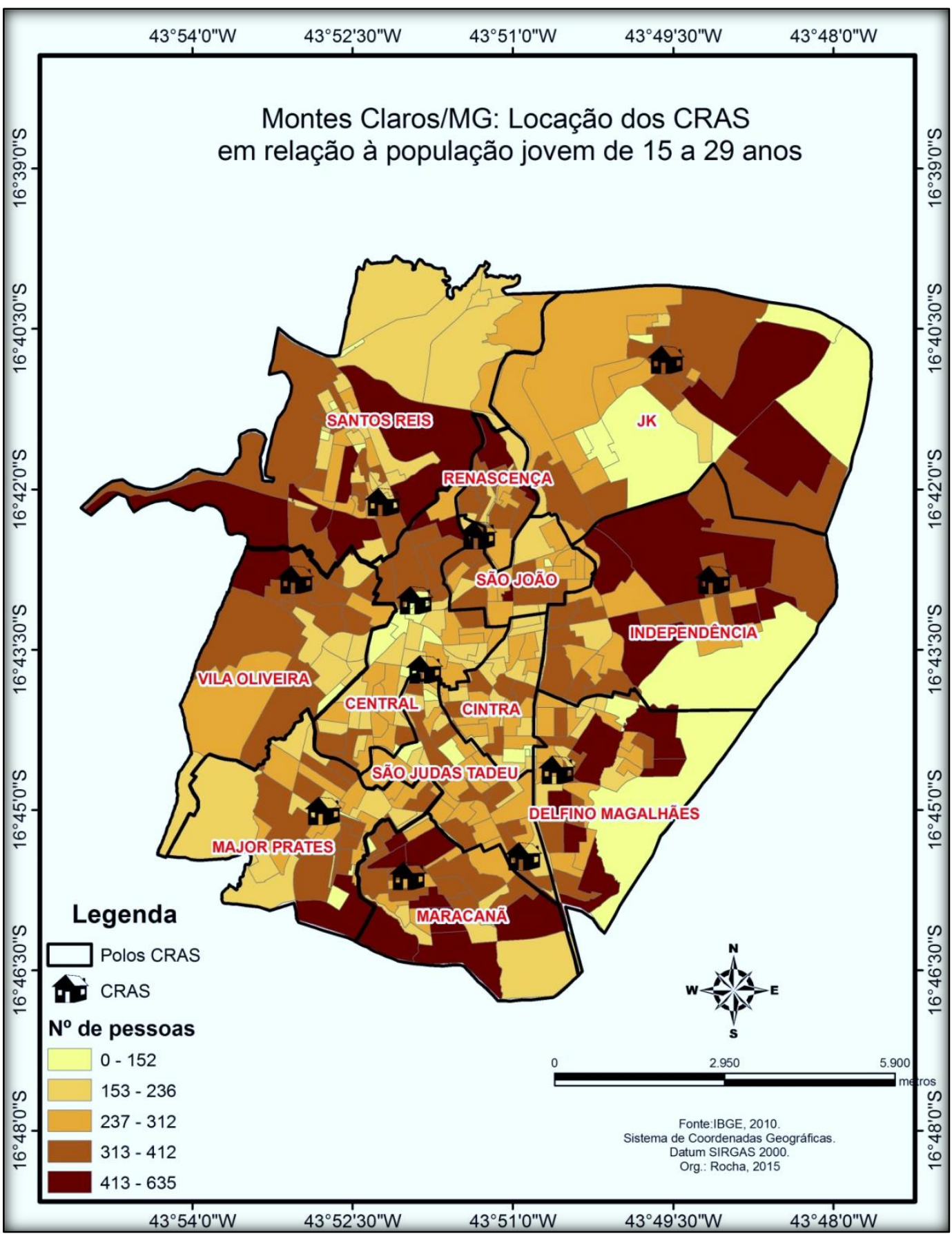

Fonte: Rocha, 2016

Uma vez apontadas as disparidades na divisão territorial e locação das unidades de CRAS, buscou-se conhecer a percepção das/dos assistentes sociais atuantes em cada unidade quanto à atuação nestes territórios e a efetividade no alcance às demandas. 0 quadro de assistentes sociais das unidades de CRAS de Montes Claros é composto, em sua maioria, por quatro profissionais, em que duas atuam pela manhã e duas pela tarde, cumprindo a lei das 30 horas semanais, conquista recente da categoria. Esta pesquisa 
alcançou 50\% destas profissionais, sendo ouvidas, por turno, as profissionais que se disponibilizaram a participar desta. As entrevistas aconteceram no período de 29 de junho a 24 de julho de 2015.

\section{Percepção das assistentes sociais quanto aos seus territórios de atuação}

Através de entrevistas semiestruturadas apresentou-se às assistentes sociais atuantes em cada território dos CRAS o objeto da pesquisa, afirmando o questionamento em torno da divisão territorial da malha urbana de Montes Claros e o atendimento às demandas de cada território como foco do trabalho. Obteve-se um levantamento geral das ações desenvolvidas pelos CRAS em atendimento a cada segmento sobre o qual se levantou dados neste trabalho, como também de características estruturais que foram observadas em todas as unidades de CRAS. Quanto aos territórios e seus empecilhos para acesso do público alvo às unidades de CRAS, em territórios muito extensos e marcados pela presença de vazios urbanos entre setores censitários houve a proposta de fragmentação dos mesmos e locação de nova unidade de CRAS; em territórios menos extensos houve proposta de relocação de setores e houve territórios em que se julgou não haver necessidade de reconfigurações territoriais.

O quadro 01 sintetiza as ponderações realizadas pelos/pelas assistentes sociais quanto à configuração de seus territórios e atendimento às demandas que estes apresentam. 


\begin{tabular}{|c|c|c|c|c|c|}
\hline Polo & $\begin{array}{l}\text { Extensão } \\
\mathrm{Km}^{2}\end{array}$ & $\begin{array}{l}\text { № de } \\
\text { setores } \\
\text { censitários }\end{array}$ & $\begin{array}{l}\text { № de famílias } \\
\text { referenciadas } \\
\text { ao CRAS }\end{array}$ & $\begin{array}{l}\text { Dificultores de } \\
\text { acesso }\end{array}$ & Reconfigurações territoriais propostas pelos/pelas Assistentes Sociais \\
\hline Maracanã & 7.49 & 39 & 3.000 & $\begin{array}{l}\text { *Distâncias } \\
\text { *Presença do anel } \\
\text { rodoviário sul }\end{array}$ & $\begin{array}{l}\text { *Agregar o "bairro" Santo Inácio ao Polo São Judas } \\
\text { *Dividir o Polo Maracanã tomando como base o anel rodoviário sul, alocando-se uma } \\
\text { nova unidade de CRAS que atenda aos "bairros" Olga Benário, Residencial Sul, Santo } \\
\text { Amaro e adjacências. } \\
\text { *Implante de aparatos públicos que atendam especificamente aos residenciais } \\
\text { populares, uma vez que geralmente se encontram em locais isolados e distantes das } \\
\text { entidades prestadoras de assistência em geral. }\end{array}$ \\
\hline Santos Reis & 17.57 & 47 & 6.480 & $\begin{array}{l}\text { *Grande extensão do } \\
\text { território. } \\
\text { *Extensos vazios } \\
\text { urbanos. } \\
\text { *Presença da BR } 135\end{array}$ & $\begin{array}{l}\text { *Fragmentação do território de forma que os "bairros" Castelo Branco, Residencial } \\
\text { Vitória, Vila Cedro, Distrito Industrial e adjacências sejam atendidos por nova unidade } \\
\text { de CRAS. } \\
\text { *Implante de aparatos públicos que atendam especificamente aos residenciais } \\
\text { populares, uma vez que geralmente se encontram em locais isolados e distantes das } \\
\text { entidades prestadoras de assistência em geral. }\end{array}$ \\
\hline Independência & 14.01 & 31 & 3.660 & $\begin{array}{c}\text { *Isolamento } \\
\text { *Locação em via com } \\
\text { declive, sem } \\
\text { pavimentação. } \\
\text { *Grande extensão do } \\
\text { território. } \\
\text { *Extensos vazios } \\
\text { urbanos. }\end{array}$ & $\begin{array}{l}\text { * Legalização da pertença dos "bairros" Belvedere I, Belvedere II e São Bento, uma } \\
\text { vez que ainda não se sabe a qual unidade de CRAS estes de fato pertenceriam. } \\
\text { População procura atendimento no CRAS Independência. } \\
\text { *Fragmentação do território e locação de nova unidade de CRAS que atenda aos } \\
\text { "bairros" Chácara Ceres, Esplanada, Guarujá, Interlagos, Monte Carmelo I, Monte } \\
\text { Carmelo II, Parque Pampulha, Regina Peres, Santa Laura, Santa Lúcia I e Santa Lúcia II. }\end{array}$ \\
\hline Vila Oliveira & 8.81 & 13 & 1.800 & Não há & Não foram apontadas reconfigurações necessárias ao polo. \\
\hline
\end{tabular}




\begin{tabular}{|c|c|c|c|c|c|}
\hline Polo & $\begin{array}{l}\text { Extensão } \\
\mathrm{Km}^{2}\end{array}$ & $\begin{array}{l}\text { № de } \\
\text { setores } \\
\text { censitários }\end{array}$ & $\begin{array}{l}\text { № de famílias } \\
\text { referenciadas } \\
\text { ao CRAS }\end{array}$ & $\begin{array}{l}\text { Dificultores } \\
\text { do acesso }\end{array}$ & Reconfigurações territoriais propostas pelos/pelas Assistentes Sociais \\
\hline $\begin{array}{l}\text { Central } \\
\text { e } \\
\text { Cintra }\end{array}$ & $\begin{array}{l}6.13 \\
2.89\end{array}$ & 51 & 3.663 & Não há & $\begin{array}{l}\text { *Acréscimo dos "bairros" Vila Luiza, Clarindo Lopes e Francisco Peres ao CRAS Central, } \\
\text { uma vez que se aproximam desta unidade. Atualmente os setores pertencem ao CRAS } \\
\text { São Judas e a população usuária não concorda com esta pertença apontando que } \\
\text { deveriam estar referenciados ao CRAS central. }\end{array}$ \\
\hline São Judas & 4.42 & 38 & 3.553 & Não há & $\begin{array}{l}\text { *Acréscimo dos "bairros" Santo Inácio e Vila Sion ao Polo São Judas, uma vez que } \\
\text { moradores destes setores procuram nesta unidade o atendimento de que necessitam. } \\
\text { Os "bairros" citados atualmente pertencem, respectivamente, aos polos Maracanã e } \\
\text { Delfino Magalhães. } \\
\text { *Retirada dos "bairros" Clarindo Lopes, Francisco Peres e João Botelho do CRAS São } \\
\text { Judas e locação dos mesmos ao Polo Central, uma vez que se aproxima mais deste e a } \\
\text { população procura neste os serviços de que necessita. }\end{array}$ \\
\hline Jk/Village & 20.86 & 27 & 3.395 & $\begin{array}{l}\text { *Grande } \\
\text { extensão do } \\
\text { território. } \\
\text { *Extensos } \\
\text { vazios } \\
\text { urbanos. }\end{array}$ & $\begin{array}{l}\text { *Fragmentação do território e locação de nova unidade de CRAS que atenda os setores } \\
\text { Jardim Primavera, JK, Monte Sião, Universitário, Planalto, e adjacências. } \\
\text { *Aparatos que atendam aos residenciais. }\end{array}$ \\
\hline $\begin{array}{l}\text { Delfino } \\
\text { Magalhães }\end{array}$ & 8.88 & 35 & 4.405 & Não há & Não foram apontadas reconfigurações territoriais necessárias. \\
\hline $\begin{array}{l}\text { Renascença } \\
\text { e } \\
\text { São João }\end{array}$ & $\begin{array}{l}1.98 \\
2.98\end{array}$ & $\begin{array}{l}15 \\
24\end{array}$ & 3.200 & Não há & Não foram apontadas reconfigurações territoriais necessárias. \\
\hline $\begin{array}{l}\text { Major } \\
\text { Prates }\end{array}$ & 8.43 & 40 & 3.553 & Não há & Não foram apontadas reconfigurações necessárias ao polo. \\
\hline
\end{tabular}

Fonte: Entrevistas junto às Assistentes Sociais da cidade de Montes Claros, 2015. 
A figura 06 demonstra a configuração territorial que de fato se encontra posta para o trabalho da assistência social em Montes Claros, em que o Polo Cintra se une ao Polo Central e o Polo Independência se une ao Polo São João. Desta forma se têm na realidade dez polos urbanos de atuação da assistência social, cada qual contendo uma unidade de CRAS, sendo que no Polo central se encontra alocada também a unidade de CRAS rural.

Figura 06: Territórios urbanos da Política de Assistência Social - Fusão Renascença/ São João e Central/Cintra.

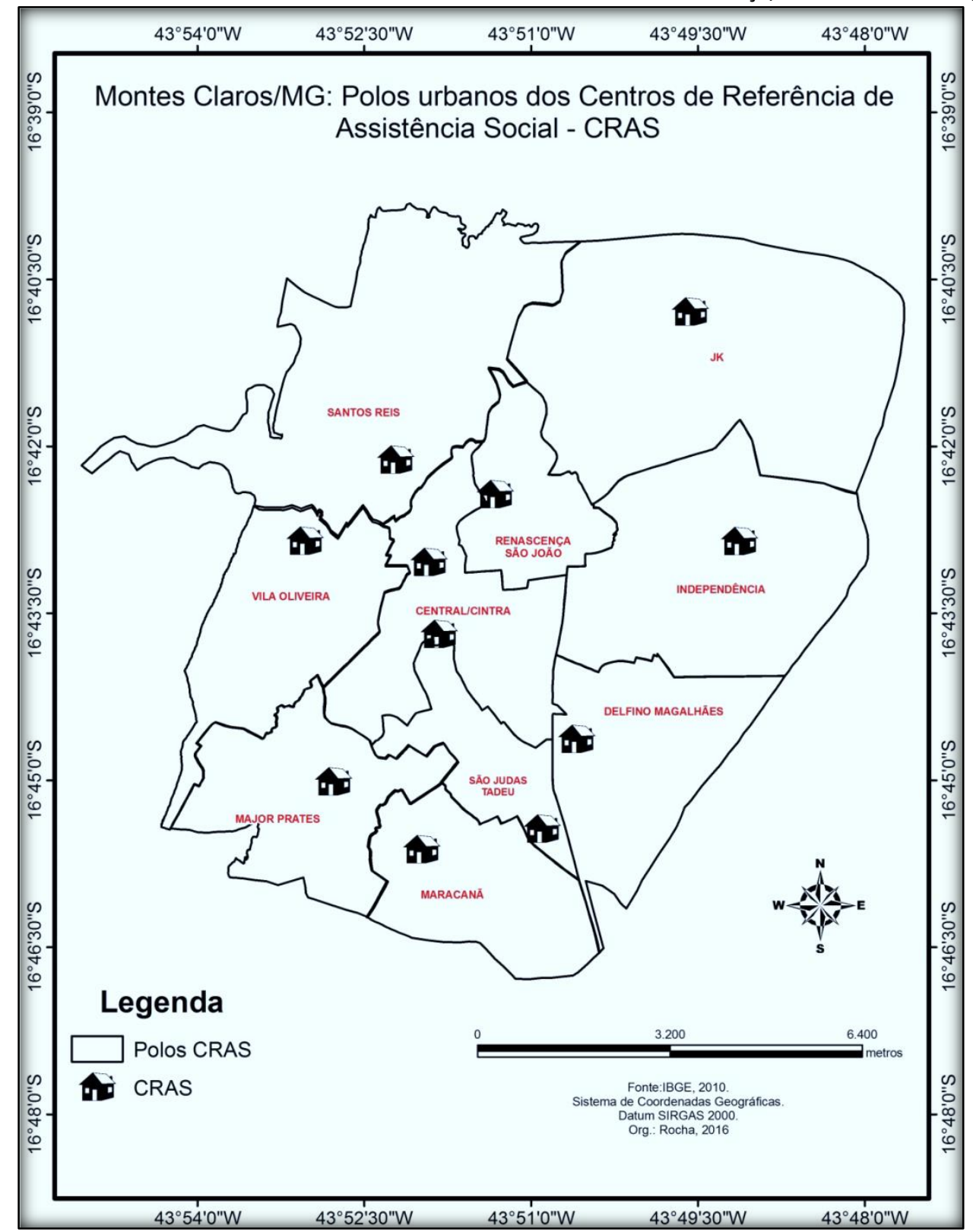

Fonte: Rocha, 2016.

A figura 07, por sua vez, simula a fragmentação territorial proposta pelas/pelos assistentes sociais atuantes em territórios extensos, sendo estes os Polos Santos Reis, Maracanã, JK/Village e Independência, que na figura 06 aparecem em suas versões I e 
II, de forma que os Polos descritos como I compreendem o correspondente à unidade de CRAS da configuração atual; a versão II simboliza a nova territorialização, que receberia novas unidades de CRAS, sendo estas o Santos Reis II, Maracanã II, JK/Village II e Independência II. A simulação foi construída tomando como parâmetro as sugestões apontadas pelas/pelos profissionais através do quadro I, mostrado anteriormente.

Figura 07- Mapa da reconfiguração territorial proposta pelas/pelos assistentes sociais para atuação da Política de Assistência Social em Montes Claros/MG.

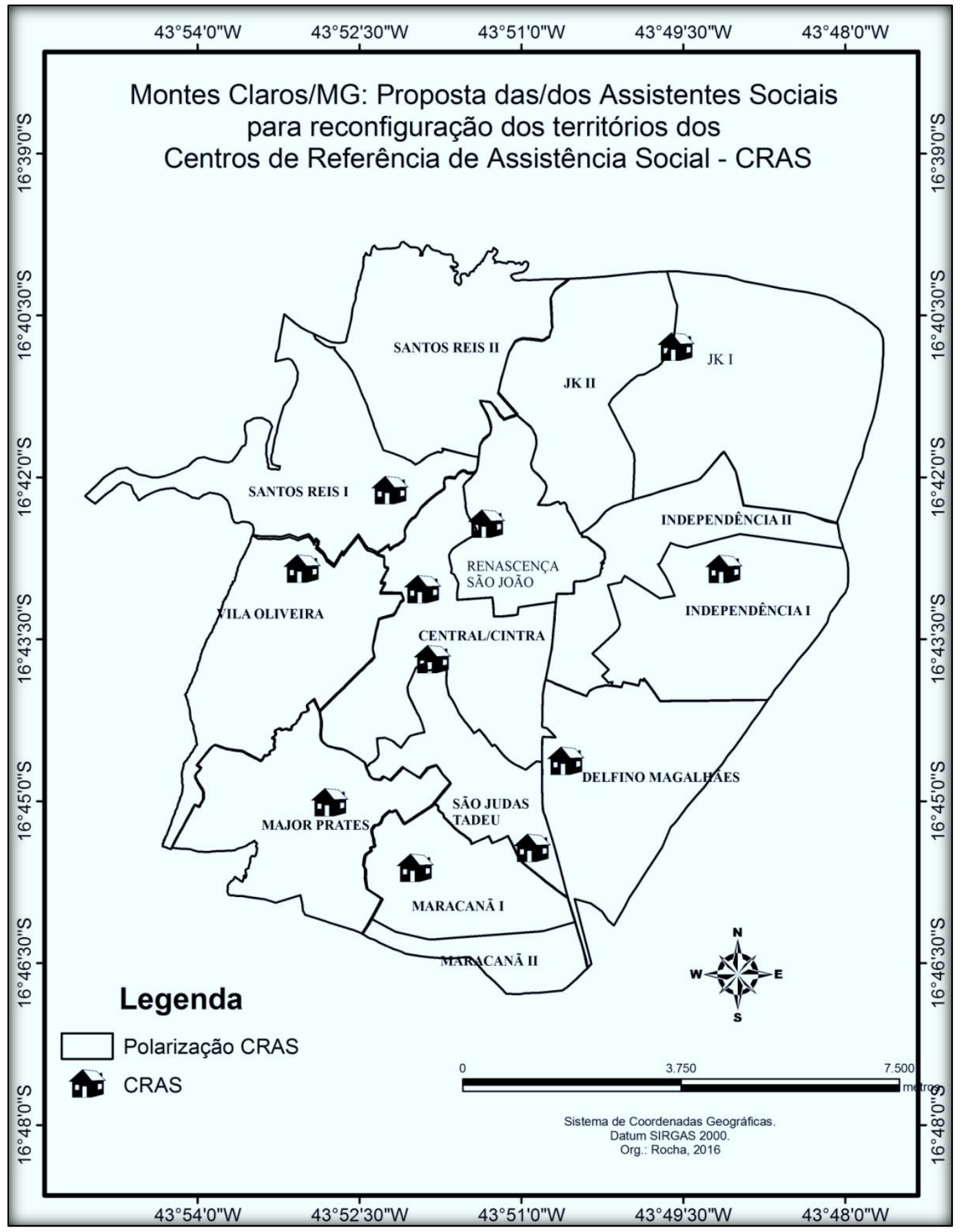

Fonte: Rocha, 2016. 


\section{Análises e reconstruções}

O que se observa, a partir da análise do número de famílias cadastradas nas unidades de CRAS e do número de domicílios de baixa renda nos territórios, é que o Polo Santos Reis figura como prioritário em necessidade de reconfiguração territorial, uma vez que o atual número de famílias cadastradas no CRAS deste território já excede o que prevê a Norma Operacional Básica do SUAS para municípios com o porte populacional de Montes Claros, sobrecarregando a equipe de profissionais.

O Polo Maracanã possuía, no ano de 2010, 4.703 domicílios de baixa renda e atualmente se encontra com 3.000 destes referenciados ao CRAS. Seria necessário um levantamento atual de dados para saber se houve aumento do número destes para além dos 5.000 domicílios/famílias, limite por unidade de CRAS determinado pela Norma do SUAS. Não foi possível a esta pesquisa, neste momento, empreender este levantamento atualizado devido ao fato de que neste trabalho se utiliza a base de dados do IBGE, que disponibiliza informações a cada dez anos. Seria necessário acesso a outros meios de levantamento de dados, para o que não houve tempo no momento, devido aos prazos a cumprir no Mestrado acadêmico. Confirmado o aumento do número de domicílios para além dos 5.000, se confirmaria a necessidade de fragmentação territorial e implante de nova unidade de CRAS que atendesse ao excesso apresentado pelo atual território.

O Polo Independência possuía, no ano de 2010, 3.491 domicílios de baixa renda e atualmente se encontra com 3.660 famílias referenciadas, número que ainda se distancia do limite previsto pela Política de Assistência (5.000 famílias cadastradas segundo o porte do município). Caso dados recentes confirmem que o território possui menos de 5.000 famílias/ domicílios de baixa renda, poderia se tornar oneroso para o poder público municipal empreender a sua fragmentação e locação de nova unidade de CRAS, para atendimento a um número pequeno de famílias em relação ao total limite para as unidades de CRAS do município. O mesmo se observa quanto ao Polo Jk, cujo número de domicílios de baixa renda era de 2.865 no ano de 2010 e se encontra atualmente com 3.395 famílias referenciadas ao CRAS, número ainda inferior ao limite estabelecido.

A cidade de Montes Claros é configurada de tal forma que os aglomerados populacionais que compõem cada loteamento, em polos como Santos Reis, 
Independência e Jk, são marcados pela presença de grandes extensões de terras desocupadas, os vazios urbanos. Assim, as unidades de CRAS nestes polos, mesmo não alcançando o número máximo de 5.000 famílias referenciadas, segundo o porte do município, encontram dificuldades em atender às demandas que possuem. Diante deste quadro conclui-se que, em territórios cujo número de famílias de baixa renda excede a quantidade estabelecida pela Norma Operacional Básica do SUAS, para o porte do município, há necessidade de fragmentação do território e locação de nova unidade de CRAS, sendo estes o Polo Santos Reis e possivelmente o Polo Maracanã. Aos territórios cujo número de famílias de baixa renda não atinge o limite estabelecido, mas existem elementos que promovem a dispersão populacional, sugere-se o implante de equipes volantes de assistência social, sendo estes os Polos Independência e JK/Village.

O trabalho denominado "volante" no município é realizado apenas pelo CRAS rural, em atendimento a 173 comunidades, que juntas somavam 4.746 famílias no ano de 2010. Deste total, 907 domicílios possuíam renda per capita mensal de até $1 / 4$ de salário mínimo e 72 domicílios possuíam renda de $1 / 4$ a $1 \frac{1}{2}$ salário mínimo per capita mensal. Na unidade de CRAS rural se encontram referenciadas atualmente, segundo informam assistentes sociais atuantes nesta unidade, 1.891 famílias.

Apesar de que apenas a zona rural contar com o trabalho volante do CRAS, uma especificidade dos polos urbanos Independência e JK/Village, qual seja a dispersão da população em função dos loteamentos vazios, leva esta pesquisa a apontar que o trabalho de equipes volantes poderia ser adotado também por estas duas unidades de CRAS urbanos, em que se observa a realidade de dispersão populacional e problemas de acesso dos usuários ao serviço, bem como dificuldades da equipe técnica em realizar a busca ativa e articulação da rede socioassistencial em benefício dos usuários dispersos.

O Ministério do Desenvolvimento Social e Combate à Fome disponibiliza aos CRAS orientações referentes à composição, financiamento e procedimentos do trabalho volante. Informa que o CRAS volante não é uma instância independente de um CRAS sede, mas sim uma extensão deste, atuando em territórios onde ocorre dispersão populacional. O trabalho do CRAS volante é financiado por meio do piso básico variável, que financia as especificidades identificadas no município, para manutenção de uma equipe composta por dois profissionais de nível superior, sendo um assistente social e, de preferência, um psicólogo, e dois profissionais de nível médio (BRASIL, 2009). 
Ao assistente social, acompanhado pelo psicólogo, cabe a realização das atividades que compõem o PAIF, ou seja, acolhida, ações particularizadas, acompanhamento familiar particular ou em grupo, de acordo com as especificidades sócio territoriais e encaminhamentos (BRASIL, 2009). Também desempenha a função de técnico de referência do serviço de convivência e fortalecimento de vínculos, quando as atividades deste serviço forem desenvolvidas nas localidades atendidas pela equipe volante (BRASIL, 2009). Oferta o serviço de proteção básica no domicilio para famílias com presença de pessoas com deficiência ou idosos que dele necessitam; identifica as famílias com perfil para acesso à renda, com registro específico daquelas em situação de extrema pobreza; identifica situações de vulnerabilidade e risco social ofertando os serviços cabíveis a cada caso ou encaminhando as situações para outros serviços.

O assistente social, neste âmbito de ação, se responsabiliza por fazer um levantamento das necessidades locais relativas ao SUAS, observadas durante o trabalho volante, repassando - as ao coordenador do CRAS sede, para que sejam tomadas as devidas providências. Trata-se de uma articulação dos setores do CRAS no sentido de garantir o acesso da população aos benefícios. O MDS orienta que é fundamental a promoção de reuniões periódicas organizadas pela coordenação do CRAS sede com a sua equipe de referência e equipe volante, no sentido de planejar as ações e avaliar os resultados obtidos através da estratégia específica de deslocamento do trabalho.

Outro ponto destacado se refere ao registro das informações sobre atendimento, encaminhamento e acompanhamento às famílias. Inserção de informações sobre a relação da família com as condicionalidades ligadas ao Programa Bolsa Família, ou seja, se está havendo negligências com a saúde, a educação, se houve suspensão de benefício, enfim, todas as informações referentes aos atendimentos e encaminhamentos devem ser registradas pelo profissional.

Cada CRAS pode possuir apenas uma equipe volante, e esta se responsabiliza pela continuidade da oferta dos serviços de proteção à população dispersa pelo território, garantindo o retorno periódico da equipe a cada localidade. Fica sob sua competência o conhecimento das famílias e suas principais características, ou seja, esta equipe, e principalmente o assistente social, deve estar atento às vulnerabilidades que compõem a realidade de cada caso, possibilitando o acesso à rede de serviços, bem como tornando 
visíveis e fortalecendo as potencialidades individuais dos sujeitos envolvidos nas demandas, por meio do apoio do poder público (BRASIL, 2009).

Uma vez que a realidade urbana de Montes Claros se apresenta sob a configuração de vazios entre loteamentos, faz-se necessário que o Plano de Assistência Social seja construído levando-se em consideração esta realidade específica, adotando as estratégias necessárias para um alcance efetivo das demandas e participação da população nas atividades que visam a prevenção de riscos sociais, garantindo o viés de direto adquirido que a Constituição de 1988 bem como a Política de Assistência Social sustentam, sendo a adoção de unidades volantes estratégia válida para territórios que não possuem o número limite de famílias de baixa renda segundo o porte municipal, mas apresentam dispersão de sua população devido aos vazios urbanos.

O acesso desta pesquisa ao Plano de Assistência Social de Montes Claros possibilitou a constatação de que este não menciona a divisão territorial da cidade em territórios das Políticas de saúde e assistência social. Não há menção aos 12 polos, às características específicas de cada um e às medidas adotadas para atendê-los em suas especificidades. O Plano Plurianual da Assistência Social 2014-2017 traz menção à oferta dos Programas, Projetos, Serviços e Benefícios; descreve as entidades públicas e privadas que compõem a rede socioassistencial, bem como determina metas a serem cumpridas quanto aos Programas, Projetos, Serviços e Benefícios com os quais trabalha, porém não há menção aos territórios, suas demandas, seus históricos socioeconômicos e unidades de CRAS nestes implantados.

\section{Considerações finais}

A redução da pobreza e a promoção do desenvolvimento social dependem da constante avaliação e reconfigurações necessárias aos mecanismos legalmente criados para este fim. Faz-se necessário que os equipamentos disponibilizados para tal garantam de fato acesso e permanência do público alvo junto aos serviços prestados, com intuito de enfrentamento à pobreza em sua multidimensionalidade. Quando estes equipamentos não permitem acesso do público alvo tem-se um rompimento com a noção de direito adquirido e cria-se a noção de violação de direitos, conforme afirma Castel (2005), acentuando as expressões da questão social na atualidade. 
Percebeu-se a partir desta pesquisa que na cidade de Montes Claros os equipamentos disponíveis para atuação da assistência social não são suficientes para atendimento às demandas. A começar pela proximidade ou distanciamento das unidades de CRAS em relação ao público alvo, em que territórios extensos possuem aglomerações populacionais não atingidas pela política de assistência; em seguida se aponta que os territórios apresentam disparidades em sua dimensão e número de loteamentos componentes. A diferença dimensional ente o território mais extenso Polo JK, 20,86 km² - e o menor território - Polo Renascença, $1.98 \mathrm{~km}^{2}$ - é de 18,88 km². Os territórios extensos, devido a presença de vazios urbanos e de elementos como anéis rodoviários, dificultam acesso da população e trabalho de busca ativa da equipe técnica.

Ouvir as/os profissionais que atuam diretamente com estas questões, analisar as suas proposições e construir, a partir das técnicas do geoprocessamento, os territórios da Política, contando com a contribuição destes, figura como democratizar a construção de ações no âmbito da Política. Fala-se em participação democrática, mas pouco se age no sentido de promove-la, divulga-la, incentiva-la. Os atores envolvidos na prática cotidiana são os mais indicados em apontar as suas carências e falhas, bem como as suas potencialidades e ganhos.

Neste contexto de planejamento das ações interventivas se destaca o protagonismo das geotecnologias no estudo de realidades sociais uma vez que as geotecnologias permitem a integração de dados provenientes de bases diferenciadas, tais como IBGE, prefeitura e CADúnico, para diagnóstico das demandas apresentadas e proposição de meios efetivos de intervenção.

\section{Referências}

BRASIL. Ministério do Desenvolvimento Social e Combate à Fome. Capacita SUAS. Planos de assistência Social: diretrizes para elaboração. ISBN: 978-85-60700-08-0 V.03. Brasília, 2008.

Ministério do Desenvolvimento Social e Combate à Fome. Orientações

técnicas: Centro de Referência de Assistência Social - CRAS. 1. ed. Brasília, 2009. 72 p.

CASTEL, Robert; As metamorfoses da questão social: uma crônica do salário.

Petrópolis, RJ: Vozes, 2005. 
FARIA, Rivaldo Mauro de; BORTOLOZZI, Arlêude. Espaço, território e saúde: contribuições de Milton Santos para o tema da Geografia da Saúde no brasil. Revista R.RA' E GA. n.17, p.31-41, 2009. Editora UFPR.

LEITE, Marcos Esdras. Geoprocessamento aplicado ao estudo do espaço urbano: 0 caso da cidade de Montes Claros/MG. 2006. 118f. Dissertação (Mestrado em Geografia) - Universidade Federal de Uberlândia, Uberlândia, 2006. Disponível em: $<$ http://www.bdtd.ufu.br/tde busca/arquivo.php?codArquivo=1404> Acesso em: 01 mai. 2015.

BRITO, Jorge Luís Silva. Sensoriamento Remoto e SIG na identificação de áreas propensas à formação de favelas: o caso de Montes Claros (MG). Boletim Goiano de Geografia, vol.32, num.2, julio-diciembre, 2012, p. 159-175. Disponível em:

http://www.revistas.ufg.br/index.php/bgg/article/view/21083/12392> Acesso em: mai. 2014.

PEREIRA, Anete Marília. Cidade média e região: o significado de Montes Claros no Norte de Minas Gerais. 2007. 351 f. Tese (Doutorado em Geografia) - Universidade Federal de Uberlândia/MG, Uberlândia/Mg, 2007. Disponível em: http://www.bdtd.ufu.br/tde_arquivos/15/TDE-2009-10-08T103209Z1697/Público/Anete.pdf $>$. Acesso em: mai. 2015.

RODRIGUES, Luciene; GONÇALVES, Maria Elizete; BALSA, Casimiro Maques; TEIXEIRA, Gilmara Emília. Análise multidimensional da pobreza, vulnerabilidade e risco social para famílias de baixa renda do município de Montes Claros (MG). In: XV SEMINÁRIO SOBRE A ECONOMIA MINEIRA - 30 ANOS. Diamantina, 2012. Anais eletrônicos do XV seminário sobre a Economia Mineira - 30 anos. Diamantina, 2012. Disponível em: <http://diamantina.cedeplar.ufmg.br/2012/arquivos/An\%C3\%A1lise\%20multidimensio nal\%20da\%20pobreza.pdf >. Acesso em: jun. 2014. 